\title{
Balıkesir Üniversitesi Çağış Kampüsü rüzgar enerjisi potansiyelinin araştırılması
}

\author{
Asiye ASLAN ${ }^{1, *}$, Bedri YÜKSEL ${ }^{2}$, Tuğrul AKYOL ${ }^{2}$ \\ ${ }^{1}$ Bandırma Onyedi Eylül Üniversitesi Gönen Meslek Yüksekokulu, Elektrik ve Enerji Bölümü, \\ Gönen, Balıkesir. \\ ${ }^{2}$ Balıkesir Üniversitesi Mühendislik-Mimarlık Fakültesi Makine Mühendisliği Bölümü, Çağış Kampüsü, \\ Balıkesir.
}

Geliş Tarihi (Recived Date): 17.02.2016 Kabul Tarihi (Accepted Date): 01.04.2016

\section{Özet}

Bu çalışmada, Balıkesir Üniversitesi Çağlş Kampüsü rüzgar enerjisi potansiyeli araştırılmıştır. Deneysel sistem 2013 yılı Haziran ayında devreye alınarak performans izleme testleri yapılmıştır. 17 Temmuz 2013 tarihinden 17 Temmuz 2014 tarihine kadar kaydedilen rüzgar verileri Windographer Yazllımı kullanılarak, tablo ve şekillerle ifade edilmiştir. Elde edilen sonuçlara göre, yıllık ortalama rüzgar hız $5.276 \mathrm{~m} / \mathrm{s}$ ile 4.640 $\mathrm{m} / \mathrm{s}$ arasında değişirken, yıllık ortalama güç yoğunluğu $175 \mathrm{~W} / \mathrm{m}^{2}$ ile $97 \mathrm{~W} / \mathrm{m}^{2}$ arasında değişmektedir. Hakim rüzgar yönü kuzey ve kuzey batı yönlerindedir. 50 m'de yıllık ortalama güç yoğunluğu $145 \mathrm{~W} / \mathrm{m}^{2}$ 'dir. Bununla birlikte, bölgenin rüzgar gücü potansiyeli değerlendirilmiş ve güç potansiyeli açısından yapılan sınıflandırmaya göre zaylf lokasyon olarak belirlenmiştir.

Anahtar kelimeler: Yenilenebilir enerji, rüzgar enerjisi, rüzgar güç yoğunluğu.

\section{Investigation of wind energy potential of Balikesir University Cagis Campus}

\begin{abstract}
In this study, was investigated wind energy potential of Balikesir University Cagis Campus. The experimental system was commissioned in June 2013 and performance monitoring tests have been conducted since then. Using Windographer Software, the collected data were quantified and illustrated in the tables and figures, 17th of July 2013 till 17th of July 2014. According to the results obtained, the annual mean wind speed varied between 5.276 and $4.640 \mathrm{~m} / \mathrm{s}$, while the annual mean power density varied
\end{abstract}

\footnotetext{
*Asiye ASLAN, asiye_aslan@yahoo.com, Tel: (266) 7620868.
} 
between $175 \mathrm{~W} / \mathrm{m}^{2}$ and $97 \mathrm{~W} / \mathrm{m}^{2}$. The prevailing wind was north-northeast. The annual mean power density was $145 \mathrm{~W} / \mathrm{m}^{2}$ at $50 \mathrm{~m}$. Moreower, the wind power potential of region was evaluated and according to the classification based on power potential,it has been identified as poor location.

Keywords: Renewable energy,wind energy,wind power density.

\section{Giriş}

Rüzgar enerjisi yenilenebilir ve çevre dostu bir enerji kaynağı olarak bilinmektedir. Dünyada sınırlı fosil yakıtların tüketimi, çevre kirliliği ve küresel ısınma gibi sorunların hızla artmakta olması bir enerji kaynağı olarak rüzgar enerjisinin kullanımı önemli hale getirmektedir. Ulaşım sorunu olmaması, kullanmak için bir yüksek teknolojiye ihtiyaç duyulmaması, düşük maliyetli olması ve temiz bir enerji kaynağı olması rüzgar enerjisi avantajları arasındadır [1].

Dünya rüzgar enerji potansiyelini belirleyebilmek amacıyla Uluslararası Enerji Ajansı (IEA) tarafından çeşitli araştırmalar yapılmıştır. Bu araştırmalarda, dünya teknik rüzgar potansiyeli $53000 \mathrm{TWh} / \mathrm{y}$ ll olarak hesaplanmıștır. Bununla birlikte dünya rüzgar enerjisi kurulu gücü 2014 yılı itibarıyla 336327 MW'dır. 2014 y1lı ilk altı aylık döneminde rüzgar enerji santrallerinin güç kapasitesinde \%5.6'l1k (17613 MW) bir kapasite artış1 tespit edilmiştir. Rüzgar enerjisine yönelik uygulanan teşvikler neticesinde, dünya rüzgar enerjisi kurulu gücünde her yıl ortalama \%10'un üzerinde bir büyüme gerçekleşmiştir. Bu büyüme oranlarıyla rüzgar enerjisi, yenilenebilir enerji kaynakları içerisinde en hızlı büyüyen enerji kaynağı olmuştur [2].

Avrupa ve Asya arasında bir köprü konumunda yer alan ülkemizin üç tarafı denizlerle çevrilidir. Türkiye özellikle Marmara Bölgesi, Ege Bölgesi ile Doğu ve Güneydoğu Anadolu kıyılarında ortalama 4.5-10 m/s rüzgar hızları ile önemli bir rüzgar enerjisi potansiyeline sahiptir [1, 3]. Rüzgar enerji santrallerinin (RES) kurulu gücü ülkemizde her yıl artmakta olup, 2009 y1lında toplam kurulu rüzgar enerjisi kapasitesi 791.6 MW iken 2014 yılında kurulu gücümüz 3762.1 MW olarak gerçekleşmiştir. 2011-2014 yılları arasında rüzgar enerji santrallerinin kurulu gücündeki artış 1900 MW'tan fazladır. 2015 yılı Temmuz ayı itibariyle ise toplam kurulu güç $4192.8 \mathrm{MW}$, inşaa halindeki santrallerin toplam gücü $1687.2 \mathrm{MW}$ ve lisanslı olan rüzgar enerji santrallerinin toplam gücü 3981.4 MW'tır. Bu durum, RES'lere yönelik yapılan yatırımların önemli miktarda arttığını göstermektedir [4].

Rüzgar özellikleri ve rüzgar enerjisi potansiyelini belirlemek için dünya çapında pek çok ülkede çeşitli araştırmalar ve çalışmalar yapılmıştır. Shu [5] vd. Hong Kong bölgesinin rüzgar enerji potansiyeli ve rüzgar karakteristiklerinin istatistiksel analizini yapmışlardır. Çalışmalarında 5 farklı meteoroloji istasyonunda 6 yıl boyunca kaydedilen rüzgar verilerini Weibull dağılım modeline göre değerlendirmişlerdir. Sonuçlara göre, yıllık Weibull ölçek parametresi 2.85-10.19 m/s arasında değişirken, şekil parametresi 1.65-1.99 arasında değişmektedir. Karthikeya [6] vd. çalışmalarında Singapur rüzgar enerji kaynaklarını incelenmişlerdir. İki farklı ölçüm sistemi ile Marine Drive, Woodlands Crescent ve Pandan Gardens lokasyonlarında yapılan ölçümler neticesinde, maksimum rüzgar güç yoğunluğu değerleri sırasıyla $45 \mathrm{~W} / \mathrm{m}^{2}, 35 \mathrm{~W} / \mathrm{m}^{2}$ ve $15 \mathrm{~W} / \mathrm{m}^{2}$ olarak elde edilmiştir. Quan ve Leephakpreeda [7] Tayland merkez bölgesinin 
rüzgar enerji potansiyelini incelemişlerdir. Yıllık ortalama rüzgar hızının 3-5 m/s arasında değiştiği görülmüştür. Bölge için 1lımlı rüzgar şartları olduğu ifade edilmiş ve elektrik üretimi için $850 \mathrm{~kW}$ gücünde bir rüzgar türbini önerilmiştir. Adaramola ve Oyewola [8] Nijerya, Oyo eyalatinde 3 farklı lokasyon seçerek bölgenin rüzgar enerji performansını değerlendirmişlerdir. Çalışmalarında, 12 ile 20 yıl arasında $10 \mathrm{~m}$ yükseklikte ölçülen veriler kullanılmıştır. Aylık ortalalama rüzgar güç yoğunluğu 27.08$164.48 \mathrm{~W} / \mathrm{m}^{2}$ arasında değişirken, yıllık ortalama rüzgar güç yoğunluğu 67.28-106.60 $\mathrm{W} / \mathrm{m}^{2}$ arasında değişmektedir.

Rüzgar enerjisi uygulamaları bakımından son derece uygun bölgelere sahip ülkemizde de rüzgar özellikleri ve potansiyeli ile ilgili literatürde birçok araştırmaya rastlanmıştır. İlkılıç ve Türkbay [1] Türkiye'nin çeşitli bölgelerinde rüzgar enerjisi potansiyelini araştırmıştır. Nurdağı, Karabiga, Datça, Bandırma, Antakya, Mardin ve Kumköy bölgeleri rüzgar enerjisi sistemleri için en uygun alanlar olarak bulunmuştur. Onat ve Ersöz [9] Samandağ, Amasra ve Güney bölgeleri için iki farklı yazılım programı kullanarak detaylı bir rüzgar potansiyeli analizi yapmıştır. Araştırmacılar bu bölgelere kurulacak olan herhangi bir rüzgar çiftliği için öngörülen enerji miktarlarını ve kapasite kullanım oranlarını hesaplamıştır. Akpınar [10] 9 yıl boyunca ölçülmüş verilere göre Türkiye'nin Kuzey Doğu kıyı bölgesi boyunca (Sinop, Samsun, Ordu, Giresun, Trabzon ve Hopa) rüzgar enerjisi potansiyelini araştırmıştır. Sonuçlara göre, Sinop, Hopa, Trabzon'un daha yüksek rüzgar enerjisi potansiyeline sahip olduğu belirlenmiştir. Özgener [11] Celal Bayar Üniversitesi Muradiye Kampüsü rüzgar enerjisi potansiyelini araştırmıştır. Sonuçlara göre, ortalama rüzgar hızı için rüzgar enerjisiden ekonomik olarak elektrik üretiminin sağlanamayacağını ifade etmektedir. Küçükali ve Dinçkal [12] Türkiye'nin Batı Karadeniz Kıyı Bölgesini kapsayan çalışmasında $50 \mathrm{~m}$ yükseklikte ölçüm direği ile toplanan rüzgar verilerin istatistiksel analizini yapmıştır. Çalışmalarında rüzgar hızı ölçümlerini kullanılarak üç farklı rüzgar türbininin enerji üretim performanslarını değerlendirmişlerdir. Sonuç olarak \%17-34 arasında türbin tipine bağlı olarak kapasite faktöründe artış olabileceğini hesaplamışlardır.

$\mathrm{Bu}$ çalışmada, Balıkesir Üniversitesi Çağış Kampüsü rüzgar enerjisi potansiyeli araştırılmıştır. Deneysel sistem 2013 yılı Haziran ayında devreye alınarak performans izleme testleri yapılmıştır. 17 Temmuz 2013 tarihinden 17 Temmuz 2014 tarihine kadar kaydedilen rüzgar verileri Windographer Yazılımı kullanılarak, tablo ve şekillerle ifade edilmiştir. Bölgenin rüzgar gücü potansiyeli değerlendirilmiş ve güç potansiyeli açısından yapılan sınıflandırmaya göre zayıf lokasyon olarak belirlenmiştir.

\section{Rüzgar verileri ve değerlendirilmesi}

Bu çalışmada kullanılan veriler Balıkesir Üniversitesi Çağış Kampüsü'ne kurulan rüzgar ölçüm direğinden elde edilmiştir. Rüzgar ölçüm direği kurulurken, kampüs içerisinde diğer binalar tarafından rüzgar hızı ve yönüne engel teşkil etmeyecek bir yer seçimine dikkat edilmiştir. Deneysel sistem 2013 yılı Haziran ayında devreye alınmıştır. Rüzgar ölçüm direği ve sensörlerin görünümü Şekil 1'de, deneysel sistemin şeması ise Şekil 2'de verilmiştir. Kule 76 m, 74.5 m, 60 m, 40 m ve 20 m yüksekliklerde bulunan 5 adet rüzgar hız sensörüne, $71 \mathrm{~m}, 58 \mathrm{~m}$ ve $38 \mathrm{~m}$ yüksekliklerde bulunan 3 adet rüzgar yön sensörüne ve $1.5 \mathrm{~m}$ yükseklikte bulunan 1 adet basınç sensörüne sahiptir. Sensörler ile ölçülen tüm veriler bir dataloger ile kaydedilmiş ve değerlendirilmek üzere bilgisayar ortamına aktarılmıştır. Sistemden elde edilen veriler her 10 dakikada bir 
kaydedilmiştir. Sistem ekipmanlarının özellikleri Tablo 1'de, veri özellikleri ve çevresel faktörler ise Tablo 2'de verilmiştir.

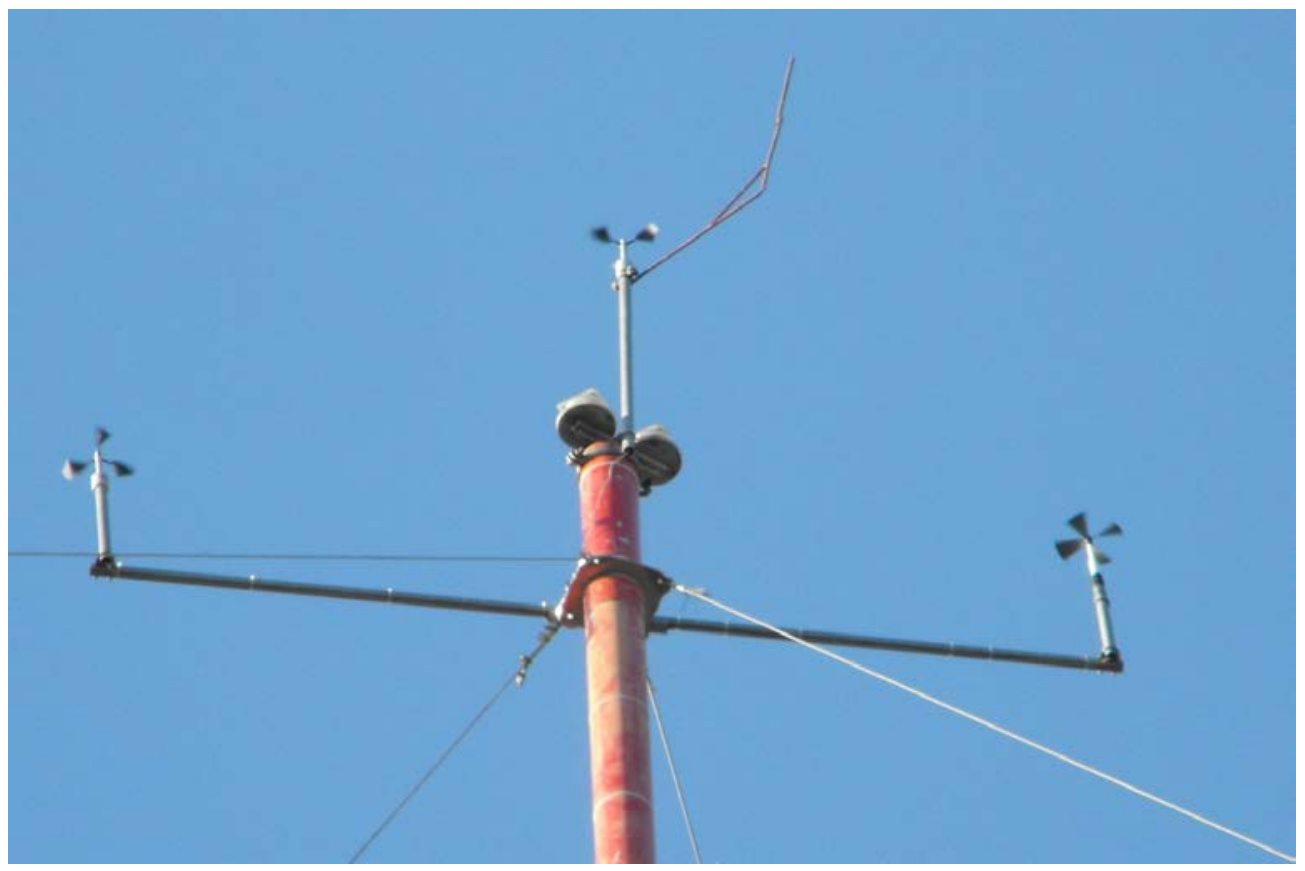

Şekil 1. Rüzgar ölçüm direği ve sensörler.

Tablo 1. Ekipman özellikleri.

\begin{tabular}{|c|c|c|c|c|}
\hline Özellikler & Anemometre & Yön sensörü & Termometre & Barometre \\
\hline Ölçüm aralığ1 & $0-40 \mathrm{~m} / \mathrm{s}$ & $0-360^{\circ} \mathrm{C}$ & -40 to $100^{\circ} \mathrm{C}$ & $800 \ldots 1100 \mathrm{hPa}$ \\
\hline Kesinlik & $\begin{aligned} 0 \ldots 15 \mathrm{~m} / \mathrm{s} & \pm 0.3 \mathrm{~m} / \mathrm{s} \\
>15 \mathrm{~m} / \mathrm{s} & \pm 2 \mathrm{~m} / \mathrm{s}\end{aligned}$ & $\pm 2 \%$ & $\pm 0.2 \mathrm{~K}$ & 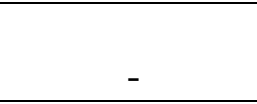 \\
\hline $\begin{array}{l}\text { Operasyon } \\
\text { sicaklık aralığ }\end{array}$ & $-50 \ldots+50^{\circ} \mathrm{C}$ & $-40 \ldots 80^{\circ} \mathrm{C}$ & $-40 \ldots 80^{\circ} \mathrm{C}$ & $\begin{array}{r}0 \ldots+85^{\circ} \mathrm{C} \\
-25 \ldots+85^{\circ} \mathrm{C} \\
\end{array}$ \\
\hline
\end{tabular}

Tablo 2. Veri özellikleri ve çevre şartları.

\begin{tabular}{|l|l|}
\hline Enlem & $\mathrm{N} \mathrm{39}^{\circ} 32^{\prime}$ 379" \\
\hline Boylam & E 028 $01^{\prime}$ 206" \\
\hline Yükseklik & $276 \mathrm{~m}$ \\
\hline Başlangıç tarihi & 17.07 .2013 11:20 \\
\hline Bitiş tarihi & 17.07 .2014 14:40 \\
\hline Süre & 12 ay \\
\hline Zaman aralığı & 10 dakika \\
\hline Ortalama sicaklık & $14 .{ }^{\circ} \mathrm{C}$ \\
\hline Ortalama basıç & $101.3 \mathrm{kPa}$ \\
\hline Ortalama hava yoğunluğu & $1.229 \mathrm{~kg} / \mathrm{m}^{3}$ \\
\hline
\end{tabular}

Elde edilen verilerin değerlendirilmesinde Windographer yazımı kullanılmıştır. Windographer rüzgar veri analiz programıdır ve Mistaya Mühendislik- Kanada yazılım şirketi ürünüdür [13]. 


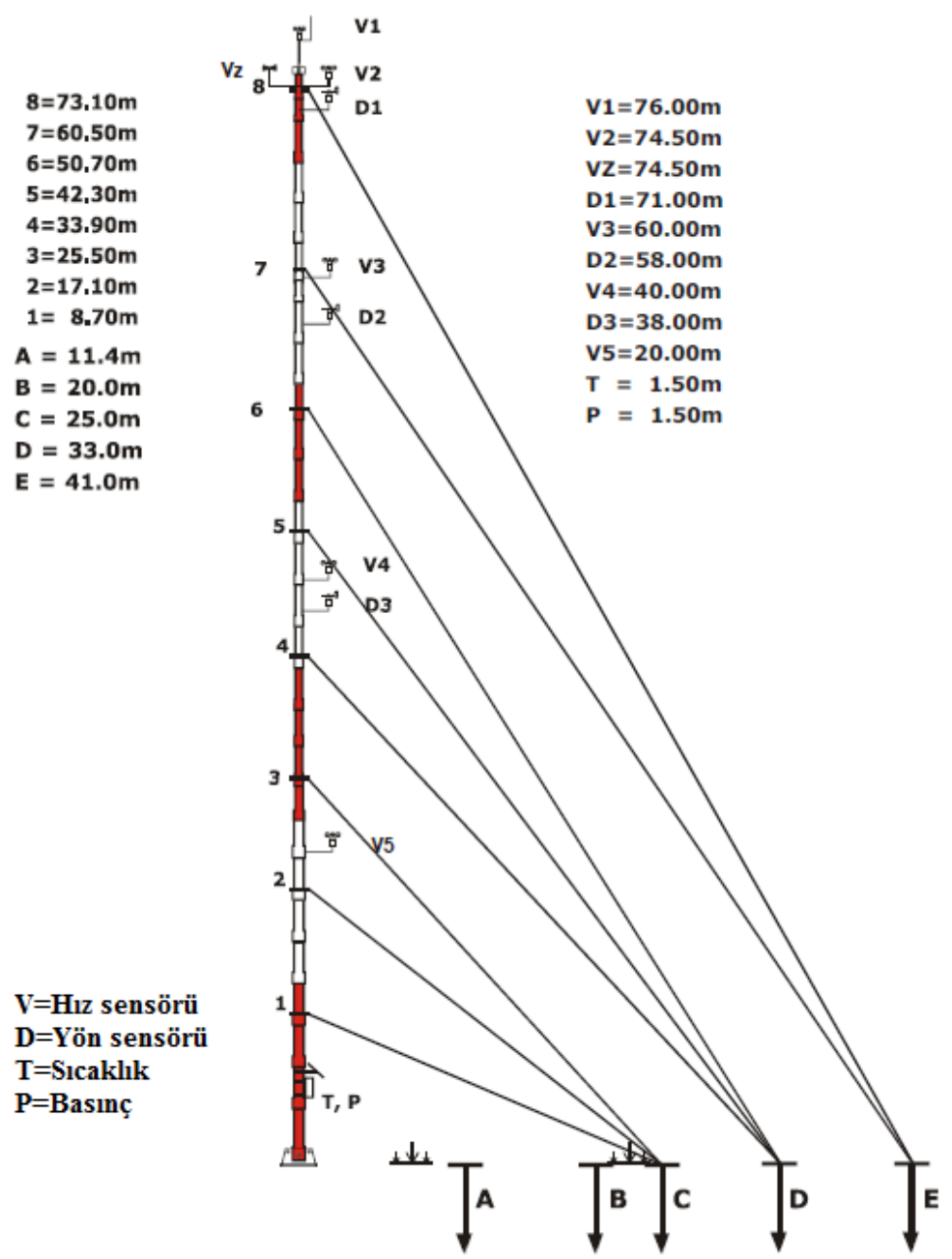

Şekil 2. Kule ve sensör yerleşim şeması.

\section{Bulgular ve tartışma}

Bu çalışmada, ölçüm sonuçlarından elde edilen veriler Balıkesir Üniversitesi Çağış Kampüsü rüzgar enerji potansiyelini belirlemek amacıyla değerlendirilmiştir. Araştırma sırasında, 12 ay boyunca ve 10 dakika sürelerle hız ve rüzgarın yönü hakkında bilgi toplanmıştır. Deneysel çalışmalar sırasında aylık ortalama hava sıcaklıkları 1.066 ile $23.790{ }^{\circ} \mathrm{C}$ arasında değiştiği gözlemlenmiştir. Deneysel sonuçlara göre hava yoğunluğu $1.229 \mathrm{~kg} / \mathrm{m}^{3}$ olarak belirlenmiştir.

Şekil 3 aylık rüzgar hız profilini vermektedir. Şekilden Temmuz ayında en yüksek ortalama hız değerinin, Aralık ayında ise en düşük ortalama hız değerinin elde edildiği görülmektedir. En yüksek aylık ortalama hız değeri V2 sensöründen $7.8469 \mathrm{~m} / \mathrm{s}$ olarak ölçülürken, en düşük aylık ortalama hız değeri V5 sensöründen $1.9936 \mathrm{~m} / \mathrm{s}$ olarak ölçülmüştür.

Şekil 4 günlük rüzgar hız profilini vermektedir. Şekilden günün ilk çeyreğinde en yüksek ortalama hız değerlerinin, ikinci çeyreğinde ise en düşük ortalama hız değerlerinin elde edildiği görülmektedir. En yüksek ortalama hız değeri V2 sensöründen $6.5377 \mathrm{~m} / \mathrm{s}$ olarak ölçülürken, en düşük ortalama hız değeri V5 sensöründen $2.3784 \mathrm{~m} / \mathrm{s}$ olarak ölçülmüştür. Şekil 5 aylara göre günlük rüzgar hız profilini vermektedir. 
Şekilden Temmuz ayında Saat:00.00 ile 06.00 arasında maksimum değere ulaşıldığ görülmektedir.

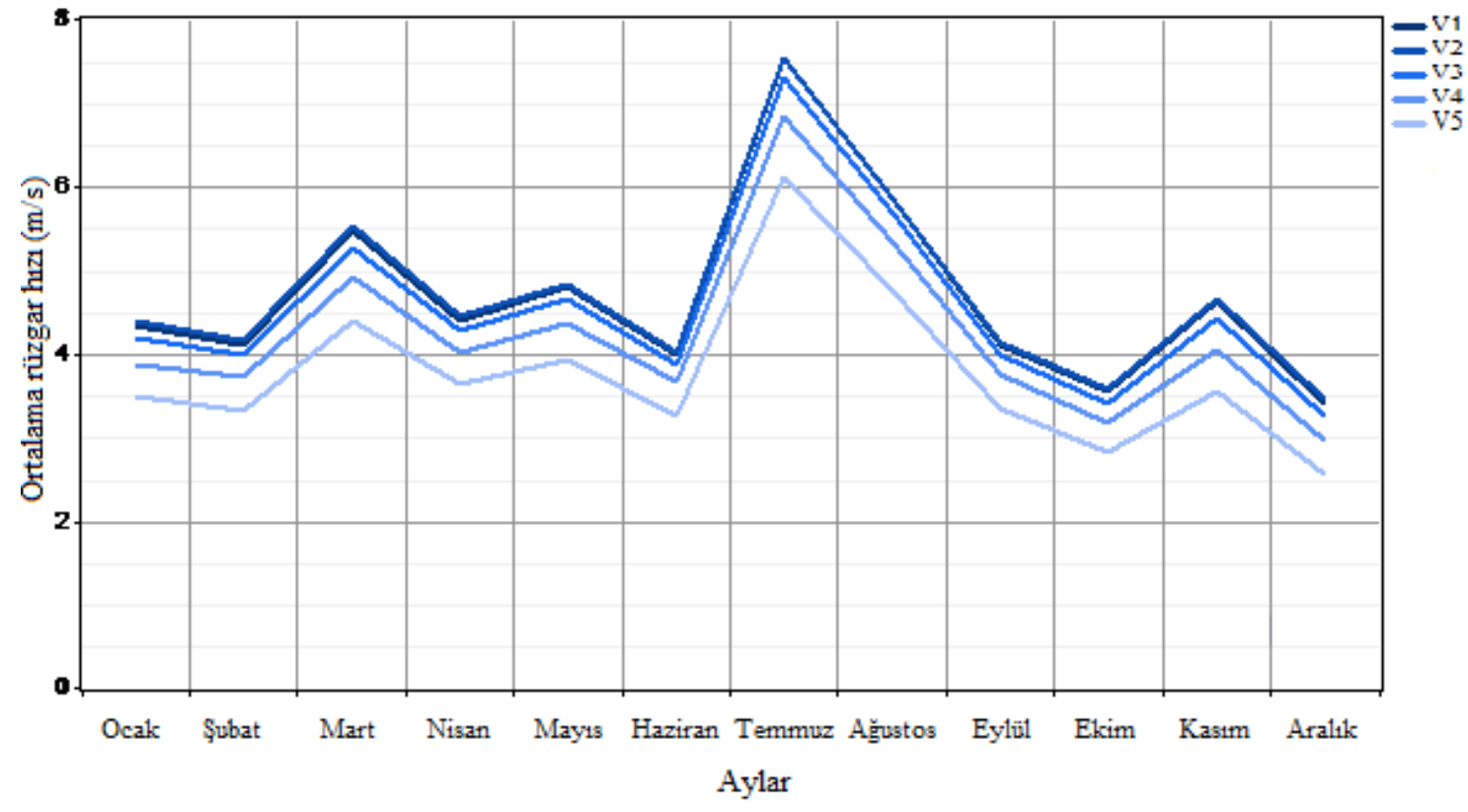

Şekil 3. Aylık rüzgar hız profili.

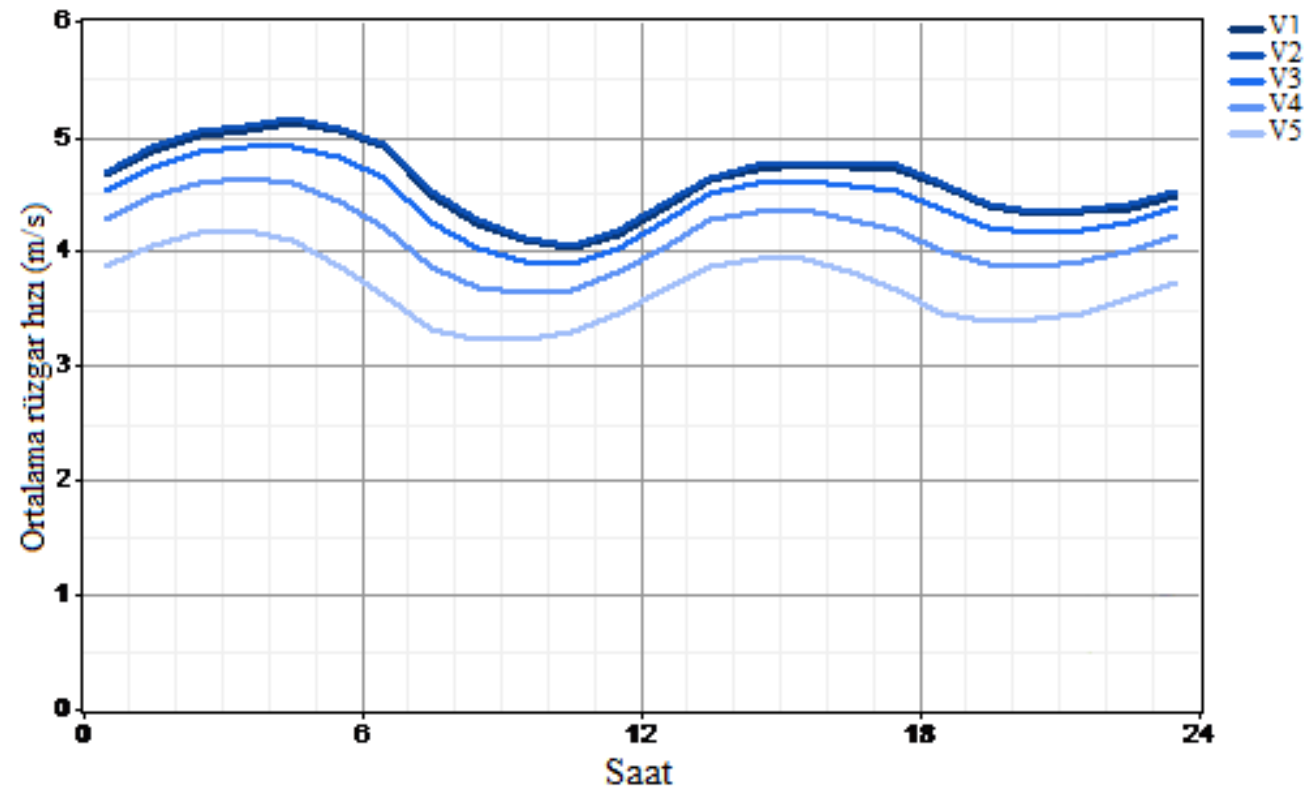

Şekil 4. Günlük rüzgar hız profili. 

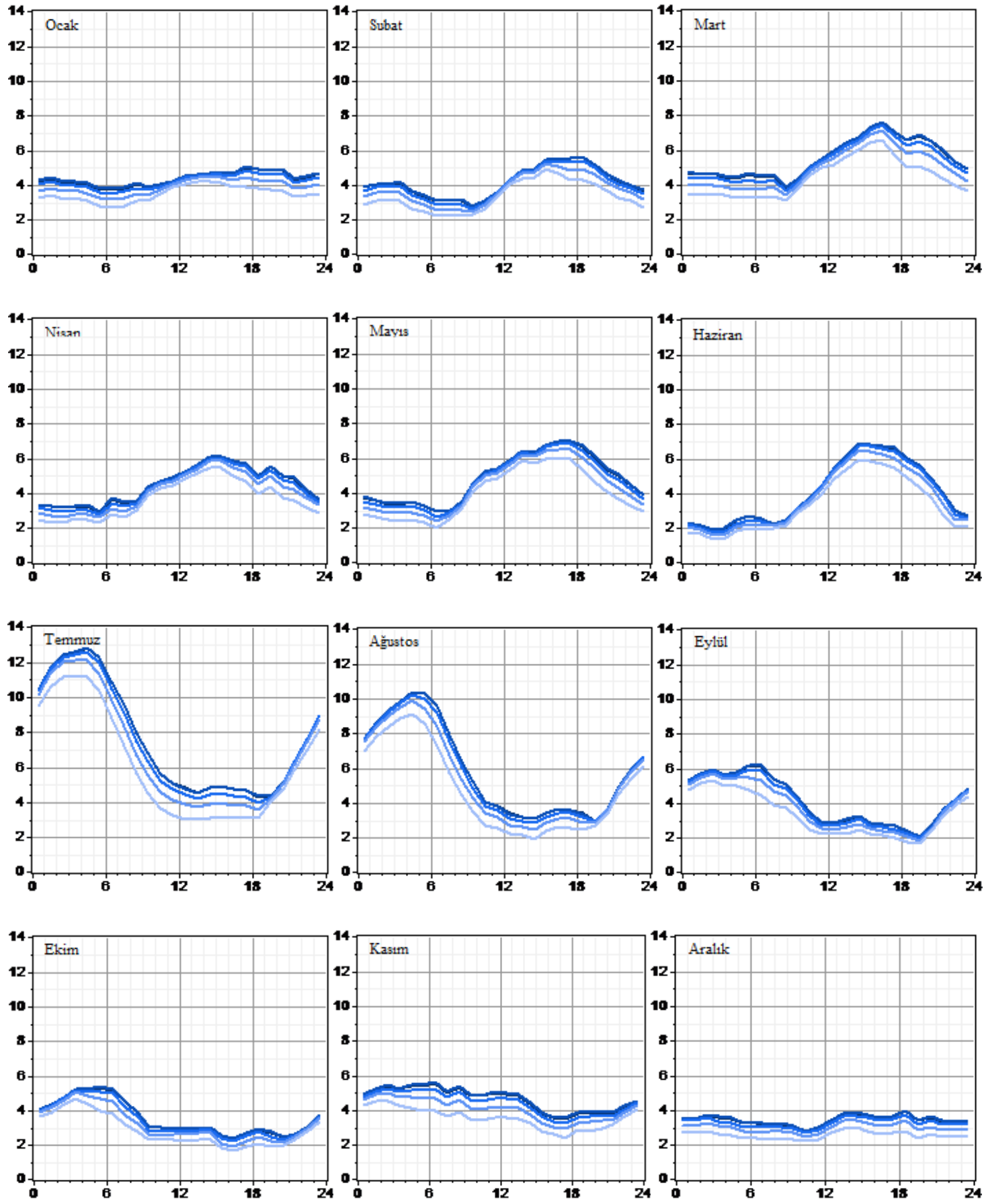

Șekil 5. Aylara göre günlük rüzgar hız profili.

Şekil 6 rüzgar yön dağılımını vermektedir. Şekilden her üç sensörle yapılan ölçümde de, hakim rüzgar yönünün kuzey ve kuzey batı yönlerinde olduğu görülmektedir. D1 sensörü için maksimum rüzgar yönü $\% 24.27$ oranında $K\left(0^{\circ}\right)$, D2 sensörü için $\% 11.15$ oranında KB $\left(292.5^{\circ}\right)$ ve D3 sensörü için \%20.27 oranında KB (337.5) olarak ölçülmüştür. 


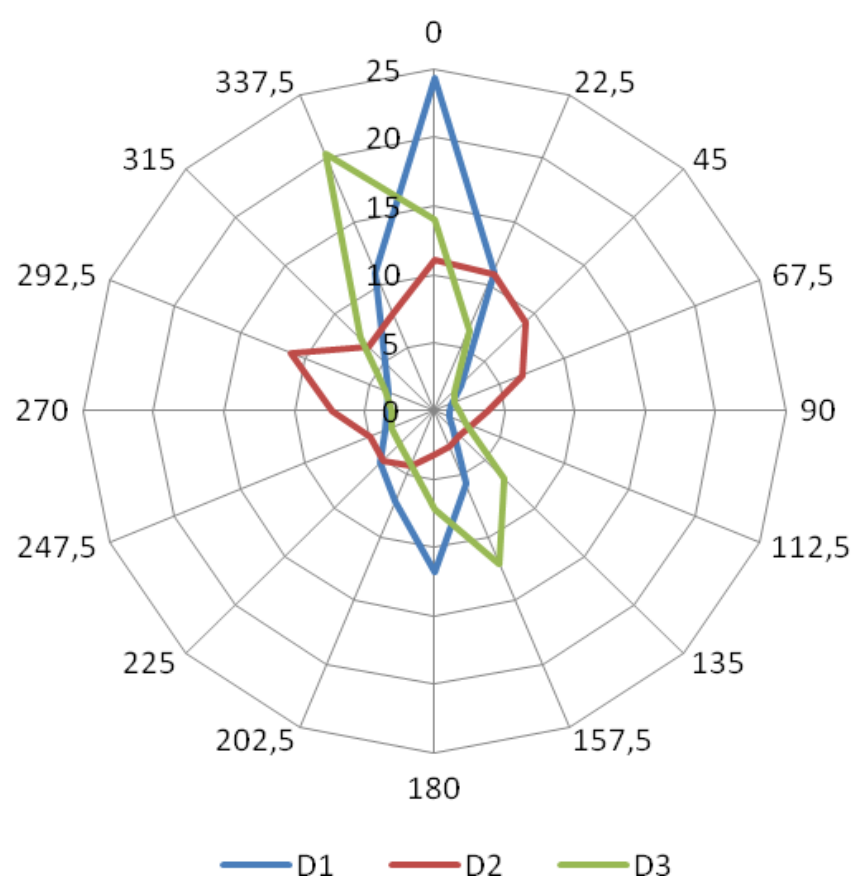

Şekil 6. Rüzgar yön dăğlımı.

Şekil 7 rüzgar hız sensörlerinden elde edilen verilere göre rüzgar hızı yoğunluk dağılımını vermektedir. Şekilden \%10.12 oranı ile en büyük değerin 1-1.5 m/s aralığında elde edildiği, bunu $\% 8.67$ oranı ile $0.5-1 \mathrm{~m} / \mathrm{s}$ aralığ $\mathrm{m} / \mathrm{s}$ aralığının takip ettiği görülmektedir.

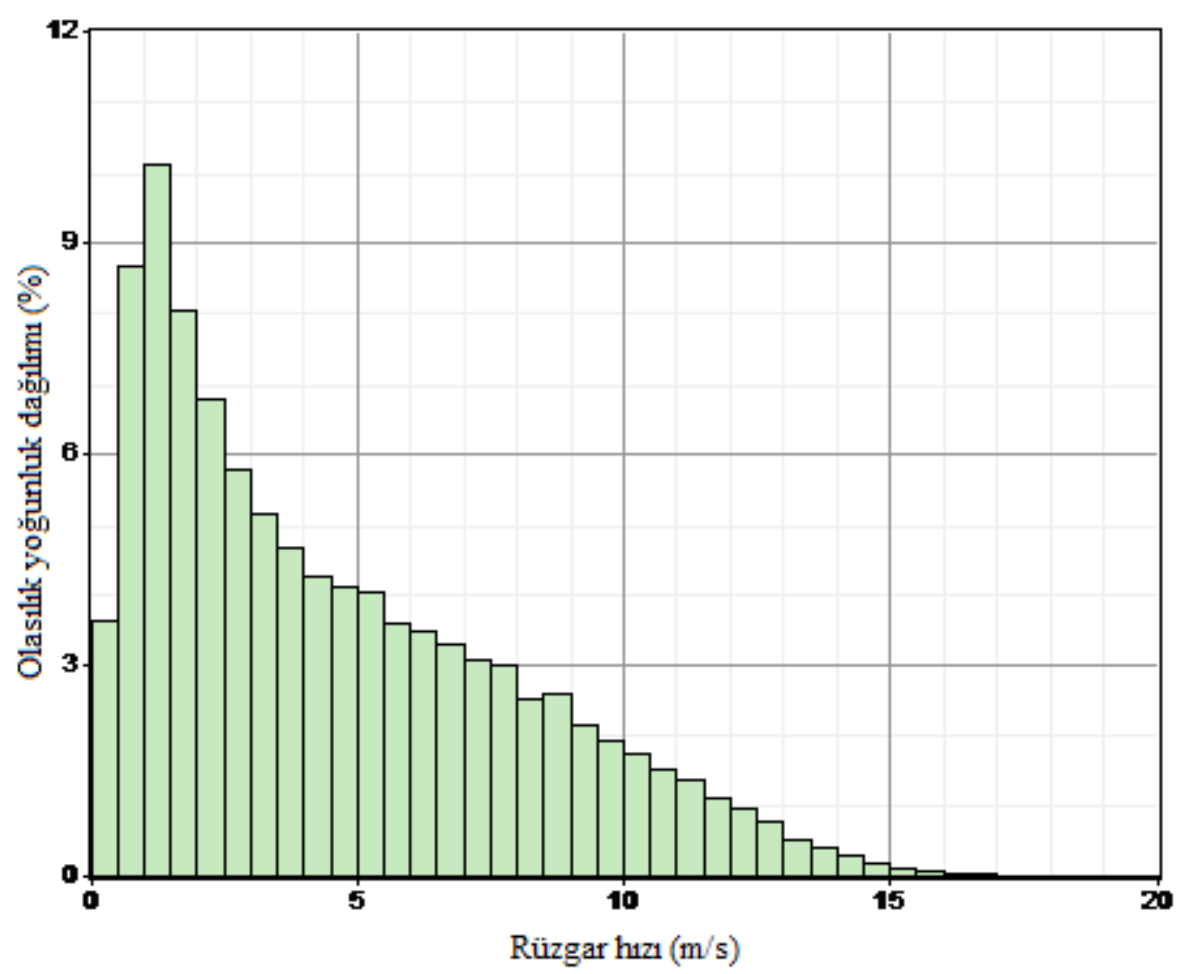

Şekil 7. Rüzgar hızı yoğunluk dağılımı. 
Şekil 8 rüzgar hız sensörlerinden elde edilen verilere göre aylık ortalama rüzgar güç yoğunluğu değerlerini vermektedir. Şekilden Temmuz ayında en yüksek rüzgar hız değerlerine paralel olarak en yüksek güç yoğunluğu değerlerinin de elde edildiği görülmektedir. Temmuz ayında en yüksek değer V2 sensöründen $450.5 \mathrm{~W} / \mathrm{m}^{2}$ olarak elde edilirken, en düşük değer $59.9 \mathrm{~W} / \mathrm{m}^{2}$ ile Ekim ayında V5 sensöründen elde edilmektedir.

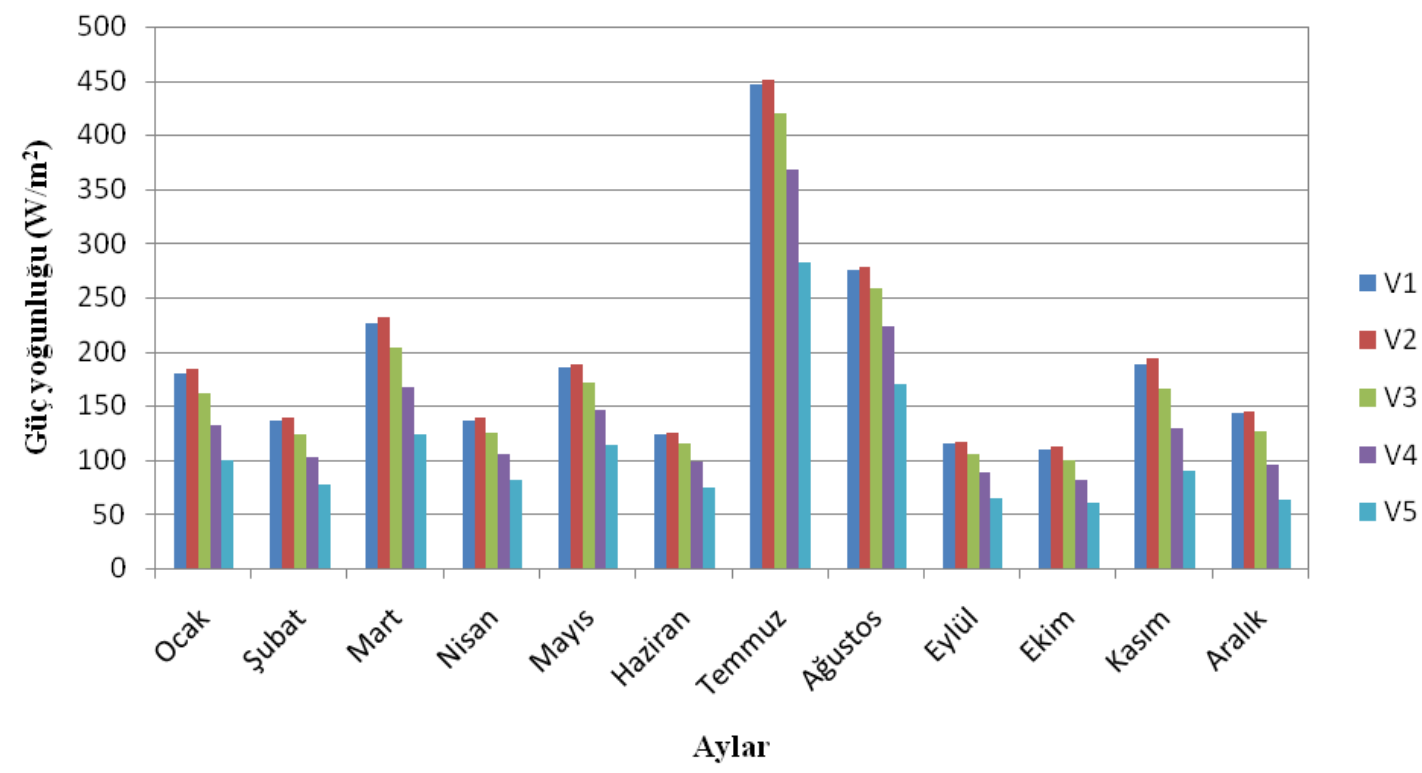

Şekil 8. Aylık ortalama rüzgar güç yoğunluğu değişimi.

Tablo 3 rüzgar hız sensörlerinden elde edilen verilere göre yıllık ortalama rüzgar hız ve güç yoğunluğu değerlerini vermektedir. En yüksek ortalama hız değeri $5.276 \mathrm{~m} / \mathrm{s}$ ile $74.5 \mathrm{~m}$ yükseklikteki V2 sensöründen elde edilirken, en düşük ortalama hız değeri ise $4.640 \mathrm{~m} / \mathrm{s}$ ile $20 \mathrm{~m}$ yükseklikteki V5 sensöründen elde edilmektedir. Hiz değerleri ile paralel olarak en yüksek ortalama güç yoğunluğu değeri V2 sensöründen $175 \mathrm{~W} / \mathrm{m}^{2}$ elde edilirken, en düşük ortalama güç yoğunluğu değeri V5 sensöründen $97 \mathrm{~W} / \mathrm{m}^{2}$ olarak elde edilmektedir.

Tablo 3. Y1llık ortalama rüzgar hızı ve güç yoğunluğu.

\begin{tabular}{|l|c|c|c|}
\hline H1z sensörü & $\begin{array}{c}\text { Sensör yüksekliği } \\
(\mathrm{m})\end{array}$ & $\begin{array}{c}\text { Ortalama hız } \\
(\mathrm{m} / \mathrm{s})\end{array}$ & $\begin{array}{c}\text { Güç yoğunluğu } \\
\left(\mathrm{W} / \mathrm{m}^{2}\right)\end{array}$ \\
\hline V1 & 76.0 & 5.237 & 172 \\
\hline V2 & 74.5 & 5.276 & 175 \\
\hline V3 & 60.0 & 4.984 & 157 \\
\hline V4 & 40.0 & 4.784 & 130 \\
\hline V5 & 20.0 & 4.640 & 97 \\
\hline
\end{tabular}

Şekil 9 rüzgar güç yoğunluğunun yüksekliğe göre değişimini vermektedir. Eğri kullanılarak 50 m'de rüzgar güç yoğunluğu $145 \mathrm{~W} / \mathrm{m}^{2}$ olarak elde edilmektedir. Rüzgar güç yoğunluğuna göre yapılan sınıflandırmada, Balıkesir Üniversitesi Çağış Kampüsü bölgesi "Sınıf 1" rüzgar güç sınıfına girmektedir. Bu değerlendirmeye göre bölge potansiyeli zayıf lokasyon olarak ifade edilebilir. 


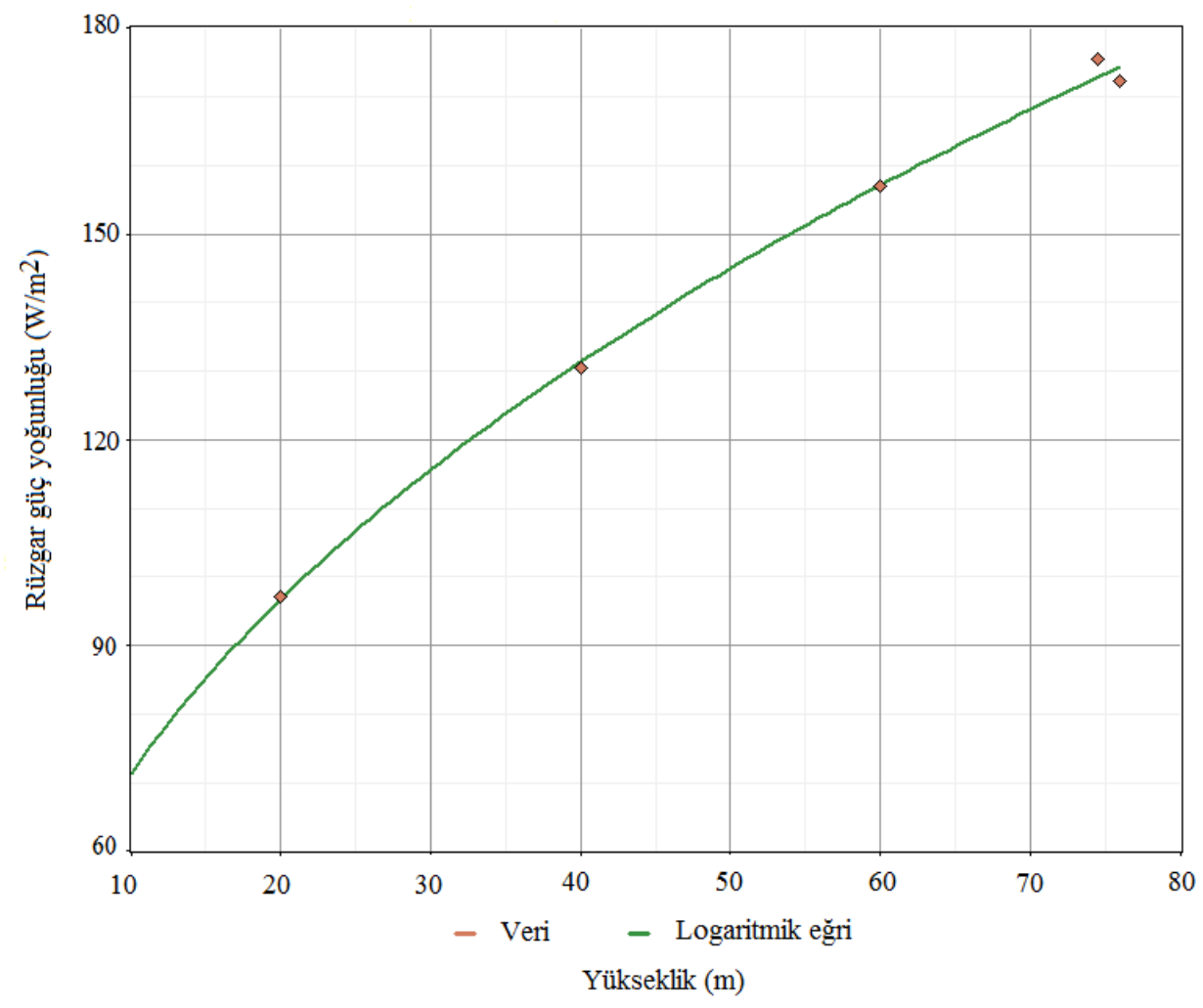

Şekil 9. Rüzgar güç yoğunluğunun yüksekliğe göre değişimi.

\section{Sonuçlar}

Bu çalışmada aşağıdaki sonuçlar elde edilmiştir.

- En yüksek yıllık ortalama hız değeri $5.276 \mathrm{~m} / \mathrm{s}$ ile $74.5 \mathrm{~m}$ yükseklikteki V2 sensöründen elde edilirken, en düşük yıllık ortalama hız değeri ise $4.640 \mathrm{~m} / \mathrm{s}$ ile 20 m yükseklikteki V5 sensöründen elde edilmektedir.

- En yüksek ortalama güç yoğunluğu değeri V2 sensöründen $175 \mathrm{~W} / \mathrm{m}^{2}$ elde edilirken, en düşük ortalama güç yoğunluğu değeri V5 sensöründen $97 \mathrm{~W} / \mathrm{m}^{2}$ olarak elde edilmektedir.

- Hakim rüzgar yönü kuzey ve kuzey batı yönlerindedir.

- 50 m'de rüzgar güç yoğunluğu $145 \mathrm{~W} / \mathrm{m}^{2}$ 'dir.

- Balıkesir Üniversitesi Çağış Kampüsü rüzgar enerjisi potansiyeli zayıf lokasyon olarak ifade edilebilir.

\section{Kaynaklar}

[1] İlkılıç, C., and Türkbay, İ., Determination and utilization of wind energy potential for Turkey, Renewable and Sustainable Energy Reviews, 14, 22022207, (2010).

[2] Şenel, M. C., ve Koç, E., Dünyada ve Türkiye'de rüzgar enerjisi durumu-Genel değerlendirme, Mühendis ve Makine, 56, 663, 46-56, (2015). 
[3] Çelik, A. N., Review of Turkey's current energy status: A case study for wind energy potential of Çanakkale province, Renewable and Sustainable Energy Reviews, 15, 2743-2749, (2011).

[4] Türkiye rüzgar enerjisi istatistik raporu, Türkiye Rüzgar Enerjisi Birliği, http://www.tureb.com.tr (25.03.2016)

[5] Shu, Z. R., Li, Q. S., and Chan, P. W., Statistical analysis of wind characteristics and wind energy potential in Hong Kong, Energy Conversion and Management, 101, 644-657, (2015).

[6] Karthikeya, B. R., Negi, P. S., and Srikanth, N., Wind resource assessment for urban renewable energy application in Singapore, Renewable Energy, 87, 403414, (2016).

[7] Quan, P., and Leephakpreeda, T., Assessment of wind energy potential for selecting wind turbines: An application to Thailand, Sustainable Energy Technologies and Assessments, 11, 17-26, (2015).

[8] Adaramola M. S., and Oyewola, O.M., Evaluating the performance of wind turbines in selected locations in Oyo state, Nigeria, Renewable Energy, 36, 3297-3304, (2011).

[9] Onat, N., and Ersöz, S., Analysis of wind climate and wind energy potential of regions in Turkey, Energy, 36, 148-156, (2011).

[10] Akpinar, A., Evaluation of wind energy potentiality at coastal locations along the north eastern coasts of Turkey, Energy, 50, 395-405, (2013).

[11] Özgener, L., Investigation of wind energy potential of Muradiye in Manisa, Turkey, Renewable and Sustainable Energy Reviews, 14, 3232-3236, (2010).

[12] Küçükali, S., and Dinçkal, Ç., Wind energy resource assessment of Izmit in the West Black Sea Coastal Region of Turkey, Renewable and Sustainable Energy Reviews, 30, 790-795, (2014).

[13] Wind resource assessment software, http://www.windographer.com (27.07.2015) 